\title{
Influence of calcium depletion on iron-binding properties of milk
}

\author{
V. A. Mittal, A. Ellis, A. Ye, S. Das, and H. Singh ${ }^{1}$ \\ Riddet Institute, Massey University, Palmerston North 4442, New Zealand
}

\begin{abstract}
We investigated the effects of calcium depletion on the binding of iron in milk. A weakly acidic cationexchange resin was used to remove 3 different levels (18-22, 50-55, and $68-72 \%)$ of calcium from milk. Five levels of iron $(5,10,15,20$, and $25 \mathrm{mM})$ were added to each of these calcium-depleted milks (CDM) and the resultant milks were analyzed for particle size, microstructure, and the distribution of protein and minerals between the colloidal and soluble phases. The depletion of calcium affected the distribution of protein and minerals in normal milk. Iron added to normal milk and low-CDM ( $\sim 20 \%$ calcium depletion) bound mainly to the colloidal phase (material sedimented at 100,000 $\times g$ for $1 \mathrm{~h}$ at $20^{\circ} \mathrm{C}$ ), with little effect on the integrity of the casein micelles. Depletion of $\sim 70 \%$ of the calcium from milk resulted in almost complete disintegration of the casein micelles, as indicated by all the protein remaining in the soluble phase upon ultracentrifugation. Addition of up to $\sim 20 \mathrm{mM}$ iron to high CDM resulted in the formation of small fibrous structures that remained in the soluble phase of milk. It appeared that the iron bound to soluble (nonsedimentable) caseins in high-CDM. We observed a decrease in the aqueous phosphorus content of all milks upon iron addition, irrespective of their calcium content. We considered the interaction between aqueous phosphorus and added iron to be responsible for the high iron-binding capacity of the proteins in milk. The soluble protein-iron complexes formed in high-CDM ( $\sim 70 \%$ calcium depletion) could be used as an effective iron fortificant for a range of food products because of their good solubility characteristics.
\end{abstract}

Key words: iron, casein micelle, calcium, milk, phosphorus

\section{INTRODUCTION}

Anemia is a global epidemic, with over 1.6 billion people being affected worldwide (McLean et al., 2009). Nutritional iron deficiency is considered to be a con-

Received June 10, 2014

Accepted December 19, 2014.

${ }^{1}$ Corresponding author: h.singh@massey.ac.nz tributory factor in at least $50 \%$ of these cases. The fortification of food with iron is considered to be a longterm strategy for solving this problem. However, iron is also considered to be the most difficult micronutrient for food fortification, because of its reactivity with food components (Richard, 1999). The direct addition of iron salts into food products may result in rancidity because of lipid oxidation (Hurrell, 2002). Chelated forms of iron have thus emerged as a convenient choice for iron fortification, as these forms have reduced ability to interact with the food components. Early studies were aimed at fortifying milk with iron (Douglas et al., 1981), whereas subsequent work looked at the ironbinding ability of milk proteins (Demott and Dincer, 1976; Gaucheron et al., 1997; Hekmat and McMahon, 1998).

The iron-binding ability of milk proteins, especially caseins, has been recognized for over 50 yr. King et al. (1959) reported that the added iron bound mainly to the serum portion of the milk and later research demonstrated that it bound mainly to the caseins in skim milk (Carmichael et al., 1975; Raouche et al., 2009a). Caseins bind $>90 \%$ of the iron added to skim milk (Demott and Dincer, 1976). The phosphorylated serine residues are the primary sites for iron binding and are frequently present in clusters of 2,3 , or 4 along the casein chain length. This clustering of the phosphoserine residues, aided by the rheomorphic character of caseins, is responsible for the high metal-binding capacity of caseins. Thus, caseins act as multidentate ligands for binding iron via coordination bonds with oxygen of the phosphorylated residues (Hegenauer et al., 1979c; Bernos et al., 1997). The binding of iron at low concentration $(\sim 1.5 \mathrm{mM})$ to the proteins in skim milk is not affected by $\mathrm{pH}(4.8-6.7)$ and ionic strength, which has been demonstrated by the successful fortification of products such as yogurt and cheese (Zhang and Mahoney, 1989; Hekmat and McMahon, 1998). The addition of iron to milk alters the distribution of minerals between the soluble and colloidal phases, with a prominent reduction in inorganic phosphorus in the soluble phase (Gaucheron et al., 1997; Raouche et al., 2009b).

At the normal $\mathrm{pH}$ of milk, its calcium content can be altered by exchanging the calcium ions with counterions on an ion-exchange resin. Ion exchange of multiva- 
lent cations (especially calcium) with monovalent ions (sodium, potassium) has been performed to improve the functionality and the stability of milk products (Lyman et al., 1933; Burgess, 1982; Bhaskar, 2010) and to manufacture novel products (Bhaskar, 2010). Up to $80 \%$ of the calcium in milk can be depleted using this technique (Ranjith et al., 1999). The depletion of calcium from milk induces changes to the structural and physicochemical properties of the milk (Burgess, 1982; Lin et al., 2006; Grimley et al., 2010), but the effects on the iron-binding properties are not known. The present work explores the effects of calcium depletion on the binding of iron to milk proteins. Furthermore, the distribution of minerals between the soluble and colloidal phases of milk is explained.

\section{MATERIALS AND METHODS}

\section{Materials}

Ultrapure class Type I water, as described by the International Organization for Standardization (ISO, 1987) with a resistivity of $18.2 \mathrm{M} \Omega \cdot \mathrm{cm}$, was used for the rinsing of glassware, the dilution of reagents, and the preparation of reconstituted milk. Analytical reagentgrade sodium hydroxide pellets and ferric chloride hexahydrate ( $>99 \%$ pure) were purchased from Sigma Aldrich (Auckland, New Zealand). Individual mineral standards for the analysis of potassium, calcium, magnesium, phosphorus, and iron were prepared using 1,000 $\pm 4 \mathrm{mg} / \mathrm{L}$ standards purchased from Fluka Analytical (Auckland, New Zealand). Low-heat skim milk powder was purchased from Fonterra Co-operative Group Ltd. (Auckland, New Zealand).

\section{Iron Fortification Process}

Low-heat skim milk powder was reconstituted in deionized water $(11 \% \mathrm{wt} / \mathrm{wt})$ at 38 to $42^{\circ} \mathrm{C}$ for $2 \mathrm{~h}$ and was kept overnight at $5^{\circ} \mathrm{C}$ to ensure complete hydration of the protein. Sodium azide at $0.02 \%$ (wt/wt) was added to the milk as a preservative. An industrialgrade, weakly acidic cation-exchange resin in $\mathrm{H}^{+}$form (Amberlite IRC86, Fluka Analytical, Lyon, France) was converted to the $\mathrm{K}^{+}$form by contacting it with 3 bed volumes of $1 M$ potassium hydroxide for $45 \mathrm{~min}$, until the wet volume of the resin increased by $80 \%$ as per the manufacturer's specification. The converted resin was washed with at least 20 bed volumes of deionized water until the $\mathrm{pH}$ of the wash water was $\sim 7$. A single batch of resin was converted and used for all experiments in our study. Milks with different levels of calcium depletion were obtained using a batch ion-exchange process $\left(5-10^{\circ} \mathrm{C}\right)$. As a spectrophotometric analysis of calcium was not feasible during the ion-exchange process, the calcium depletion from normal milk was monitored by a complexometric titration method using Patton and Reeder's indicator (Patton and Reeder, 1956). The $\mathrm{pH}$ of all the calcium-depleted milks (CDM) was readjusted to $\mathrm{pH} 6.8$ using $1 \mathrm{M}$ sodium hydroxide solution, followed by volume adjustment using deionized water. The values for minerals reported herein represent their respective contents in the $\mathrm{pH}$-readjusted samples. Iron addition to the CDM was performed after overnight chilled storage and adjustment of the $\mathrm{pH}$ to 6.8 . Freshly prepared $0.5 \mathrm{M}$ ferric chloride solution was added dropwise to the vigorously stirred milks $\left(3-6^{\circ} \mathrm{C}\right)$, with the $\mathrm{pH}$ being maintained at $\sim 6.8$ using $1 M$ sodium hydroxide. The iron-fortified milks were stirred for $30 \mathrm{~min}$ at $\sim 5^{\circ} \mathrm{C}$ and were stored overnight in a chiller $\left(4-7^{\circ} \mathrm{C}\right)$.

\section{Protein and Mineral Partitioning}

All milks were partitioned into sedimentable and nonsedimentable (soluble) phases by ultracentrifugation at $100,000 \times g$ for $1 \mathrm{~h}$ at $20^{\circ} \mathrm{C}$. The supernatant was collected by inverting the ultracentrifuged tubes. Values for minerals in the nonsedimentable phase were corrected for the excluded volume effect, as proposed by Davies and White (1960). The permeate was obtained from the supernatant after ultrafiltration using 10,000 molecular weight cut-off (regenerated cellulose) membranes (Amicon Ultra, Millipore) at 3,000 $\times g$ for $30 \mathrm{~min}$. The proportionate distribution of minerals was determined by analyzing the total content in the sample, the nonsedimentable phase, and the permeate. A constant correction factor of 0.96 was applied to the minerals estimated in the ultrafiltration permeate.

Cations (iron, calcium, magnesium, potassium, and sodium) were analyzed using a single flame atomic absorption spectrophotometer (GBC Scientific Equipment, Hampshire, IL) following wet digestion of the milks with concentrated sulfuric and nitric acids (Marshall, 2010). Typically, a $2-\mathrm{g}$ sample was digested in a 125-mL Erlenmeyer conical flask and transferred with sufficient rinsing to a volumetric flask. The wetdigested samples were then diluted approximately 50 to 200 times in deionized water depending on the cation to be analyzed. All cations, except calcium, were analyzed using the air-acetylene flame. Calcium was analyzed using the oxidizing air-nitrous oxide flame; $5,000 \mathrm{mg} / \mathrm{L}$ of lanthanum trichloride was included as the releasing agent. Phosphorus was determined by the molybdenum blue method, as described by the International Organization for Standardization (ISO, 2006). The protein content was determined by the semi-Kjeldahl method using a factor of 6.38 for converting total nitrogen content to protein content. 


\section{Particle Size and $\zeta$-Potential}

Hydrodynamic mean (Z-average) diameters and $\zeta$-potential values were obtained using dynamic light scattering (Zetasizer Nano ZS; Malvern Instruments, Malvern, Worcestershire, UK). Milk samples were diluted 100 times in the permeate of respective samples and measurements were taken in a 1-cm path-length disposable cuvette at a backscatter angle of $173^{\circ}$. The $\zeta$-potential values of the samples were determined after a 50-fold dilution with the respective permeate. Three readings were taken for each sample in duplicate. The number diameter was used to monitor the breakdown of the casein micelles upon ion-exchange treatment.

\section{Transmission Electron Microscopy}

The microstructural changes in the milks upon calcium depletion and iron addition were studied using transmission electron microscopy (TEM). Undiluted samples were injected and sealed in agarose tubes. Primary fixation and secondary fixation were performed using $3 \%$ glutaraldehyde and $1 \%$ osmium tetroxide in $0.1 M$ cacodylate buffer ( $\mathrm{pH} 7.2$ ), with buffer washings between the 2 fixations, as adapted from Karlsson et al. (2007). Dehydration of the sample was achieved using an acetone series, before infiltration and embedding in fresh resin (Procure 812; ProSciTech Pty Ltd., Thuringowa Central, Queensland, Australia). Ultrathin sections (100 nm thick) were cut using a diamond knife and an ultramicrotome (Leica, Vienna, Austria). Samples were stained for $4 \mathrm{~min}$ with saturated uranyl acetate and lead citrate before being viewed in a transmission electron microscope (Philips EM 201C, Eindhoven, the Netherlands).

\section{RESULTS AND DISCUSSION}

\section{Effect of Calcium Depletion on the Physicochemical Properties of Milk}

We achieved 3 levels of calcium depletion in this work using different volumes of ion-exchange resin (0 to $3.75 \%$ by volume of the milk). We designated the milks as low- (18-22\%), medium- (50-55\%), and high-CDM (68-72\%) depending on the level of calcium depletion. The ion-exchange treatment affected the appearance of normal milk. The removal of $>50 \%$ of the calcium resulted in a translucent greenish liquid, in agreement with the observations of Grimley et al. (2010). The highCDM was visibly less turbid than the medium CDM.

\section{Mineral Composition}

The mineral compositions of normal milk (control) and the CDM are shown in Table 1. The calcium content of normal milk was $1,097 \mathrm{mg} / \mathrm{kg}$, which was reduced to $356 \mathrm{mg} / \mathrm{kg}$ by the ion-exchange treatment. As the potassium ions on the ion-exchange resin were exchanged for calcium ions in the milk, the proportionate potassium concentration increased from 1,619 mg/ $\mathrm{kg}$ in normal milk to $2,514 \mathrm{mg} / \mathrm{kg}$ in the high-CDM. The ion-exchange treatment also affected the magnesium content of the milk, which was reduced from 82 $\mathrm{mg} / \mathrm{kg}$ in normal milk to $41 \mathrm{mg} / \mathrm{kg}$ in the high-CDM (i.e., a 50\% reduction). Ranjith et al. (1999) observed similar reductions in magnesium content when $60 \%$ of the calcium was depleted from milk. The affinity of resins for exchanging the counter-ions in solution is directly proportional to their charge and atomic number (DeSilva, 1999). This implies that a $\mathrm{K}^{+}$form of ion-exchange resin will preferably exchange $\mathrm{Ca}^{2+}$ over $\mathrm{Mg}^{2+}$ and other monovalent ions present in the exchanging medium. Moreover, as the atomic number of calcium (20) is higher than that of magnesium (12), it was preferentially exchanged during the ion-exchange process. The higher sodium contents in the CDM than in normal milk were due to the readjustment of the $\mathrm{pH}$ to 6.8 using sodium hydroxide solution.

Although a reduction in the anion concentrations is not envisaged in a cation-exchange process, reductions in total phosphorus content have been reported (Ranjith et al., 1999). In the present study, this decrease was $\sim 15$ to $20 \%$ in milks with calcium depletions of $>50 \%$ (Table 1). However, greater reductions in phosphorus content (up to 50\%) were observed in earlier studies (Lyman et al., 1933; Bishov et al., 1959; Ranjith et al., 1999). Ranjith et al. (1999) proposed that the reduction was caused by the precipitation of calcium phosphate on to the surface of the ion-exchange resin.

\section{Physicochemical Properties}

The effects of calcium depletion on selected characteristics of the milks are shown in Table 2. Calcium depletion by ion exchange was accompanied by a reduction in the $\mathrm{pH}$ of the milk, the extent being directly proportional to the amount of calcium depleted. The $\mathrm{pH}$ of the high-CDM ( $\sim 70 \%$ calcium depletion) was reduced to 6.28 after the ion-exchange treatment. A similar reduction in $\mathrm{pH}$, from 6.72 to 6.38 , was observed by Ranjith et al. (1999) upon $\sim 80 \%$ calcium depletion from milk using a comparable resin. All the treated milks were readjusted to $\mathrm{pH} 6.8$ before further analysis.

The protein content in the nonsedimentable phase of normal milk (after ultracentrifugation at 100,000 $\times g$ for $1 \mathrm{~h}$ at $20^{\circ} \mathrm{C}$ ) was $0.83 \%$ ( $26 \%$ of the total), and consisted mainly of whey proteins and some nonsedimentable casein particles (Hekmat and McMahon, 1998). The nonsedimentable protein content was higher 
Table 1. Effect of calcium depletion on the composition of minerals $(\mathrm{mg} / \mathrm{kg}$; means $\pm \mathrm{SE})$ in normal milk and different calcium-depleted milks (CDM)

\begin{tabular}{lccccc}
\hline $\begin{array}{l}\text { Milk } \\
\text { (calcium depletion) }\end{array}$ & Calcium & Potassium & Magnesium & Sodium & $\begin{array}{c}\text { Total } \\
\text { phosphorus }\end{array}$ \\
\hline Milk & $1,097( \pm 8)$ & $1,619( \pm 28)$ & $82( \pm 4)$ & $428( \pm 9)$ & $1,008( \pm 25)$ \\
Low-CDM (18 to 22\%) & $882( \pm 18)$ & $1,838( \pm 9)$ & $73( \pm 1)$ & $484( \pm 3)$ & $957( \pm 1)$ \\
Medium-CDM (50 to 55\%) & $579( \pm 10.0)$ & $2,403( \pm 25)$ & $47( \pm 2)$ & $514( \pm 5)$ & $856( \pm 19)$ \\
High-CDM (68 to 72\%) & $356( \pm 4)$ & $2,514( \pm 10)$ & $41( \pm 1)$ & $642( \pm 50)$ & $932( \pm 4)$ \\
\hline
\end{tabular}

in the CDM; $\sim 35, \sim 82$, and $\sim 94 \%$ of the total protein was found in the nonsedimentable phase of the low-, medium-, and high-CDM, respectively.

The Z-average diameters of the normal milk and the low-CDM were $\sim 260 \mathrm{~nm}$, which suggested that depletion of $\sim 20 \%$ calcium had little effect on the integrity of the casein micelles (Table 2). Similar trends were also reflected in the number diameters observed for these milks, which were $\sim 200 \mathrm{~nm}$. In the medium-CDM, the Z-average diameter reduced to $\sim 128 \mathrm{~nm}$, reflecting a decrease in the size of the casein micelles, and the number diameter showed an almost 5 -fold decrease compared with normal milk. A further reduction in the calcium content (up to $70 \%$ in the high-CDM) caused progressive disintegration of the remaining particles, as indicated by the decreasing value for the number average diameter. However, a slight increase in the Zaverage diameter was observed in the high-CDM, which was due to a small number of larger particles or structures in the system.

The average polydispersity index values were $\sim 0.168$ for both the normal milk and the low-CDM, indicating a homogeneous distribution of particles. The polydispersity index increased 2-fold upon $>50 \%$ calcium depletion (Table 2), probably because of the simultaneous existence of micellar casein particles and variably associated caseins in the dispersions of the mediumand high-CDM.

All the $\zeta$-potential values were in the range of $-16 \pm$ $1 \mathrm{mV}$, irrespective of the calcium content in the milk. In normal milk and the low-CDM, in which the casein micelle structure was largely preserved, the negative $\zeta$-potential could probably be attributed to the po- lar residues of the $\kappa$-CN on the surface of the casein micelles. However, as the casein micelle structure was substantially disintegrated in the medium- and highCDM, the negative $\zeta$-potential probably represented the surface charges on the polar residues on partially dissociated casein particles.

The TEM showed that roughly spherical casein micelles of various diameters were present in normal milk (Figure 1A). However, the casein micelles were completely disrupted upon $\sim 70 \%$ calcium removal from normal milk (Figure 1B).

The integrity of the casein micelles in milk is maintained by the balance of electrostatic repulsion forces and hydrophobic attraction forces, in which calcium phosphate nanoclusters play neutralizing and cementing roles (Horne, 1998). Disintegration of the casein micelles occurs when the balance is shifted toward electrostatic repulsion, caused by the charged residues on the caseins in the micelles.

Furthermore, the colloidal calcium of the casein micelles is in dynamic equilibrium with the calcium in the serum phase of milk (Gaucheron, 2005). Rapid transfer of colloidal calcium to the soluble phase has been demonstrated (Pierre and Brule, 1981). The ion-exchange resin binds ionic calcium in the aqueous phase of milk (Grimley et al., 2010), resulting in a transfer of micellar calcium to the soluble phase. The reduction in the micellar calcium content of the casein micelle results in an increase in the negative charge on the caseins (Ward et al., 1997). Consequently, the balance shifts in favor of electrostatic repulsion, leading to disintegration (Horne, 1998; Udabage et al., 2000) of the casein micelles, as seen in the medium- and high-CDM. However,

Table 2. Effect of calcium depletion on some physicochemical properties (means \pm SE) of normal milk and calcium-depleted milks (CDM)

\begin{tabular}{|c|c|c|c|c|c|c|}
\hline $\begin{array}{l}\text { Milk } \\
\text { (calcium depletion) }\end{array}$ & $\mathrm{pH}$ & $\begin{array}{c}\text { Soluble } \\
\text { protein (\%) }\end{array}$ & $\begin{array}{c}\text { Z-average } \\
\text { diameter (nm) }\end{array}$ & $\begin{array}{l}\text { Number } \\
\text { diameter } \\
(\mathrm{nm})\end{array}$ & $\begin{array}{l}\text { Polydispersity } \\
\text { index }\end{array}$ & $\zeta$-potential \\
\hline Low-CDM (18 to $22 \%$ ) & $6.58( \pm 0.04)$ & $1.10( \pm 0.63)$ & 258.0 & 198.9 & $0.16( \pm 0.01)$ & $-16.0( \pm 0.3)$ \\
\hline Medium-CDM (50 to $55 \%$ ) & $6.42( \pm 0.04)$ & $2.52( \pm 0.36)$ & 128.2 & 38.8 & $0.31( \pm 0.03)$ & $-15.1( \pm 0.4)$ \\
\hline High-CDM ( 68 to $72 \%$ ) & $6.28( \pm 0.06)$ & $2.99( \pm 0.10)$ & 158.0 & 20.1 & $0.45( \pm 0.03)$ & $-16.8( \pm 0.9)$ \\
\hline
\end{tabular}



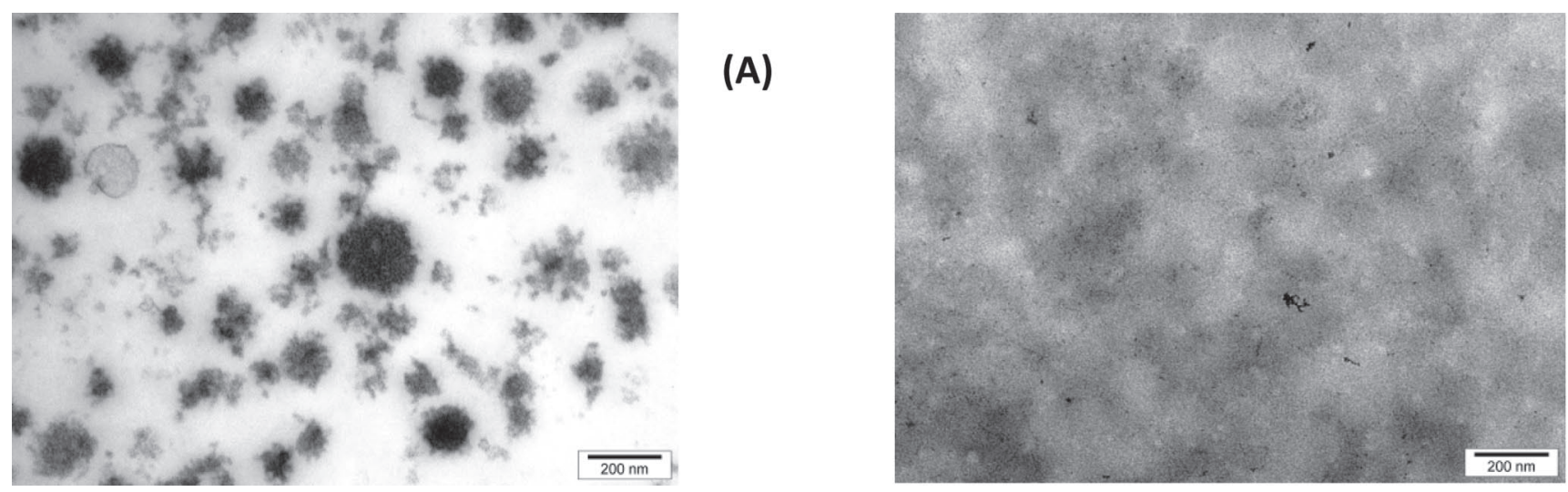

Figure 1. Transmission electron microscopy micrographs of (A) normal milk and (B) $70 \%$ calcium-depleted milk.

as the calcium content of the medium-CDM was higher than that of the high-CDM, larger amounts of calcium remained associated with the caseins in the former.

The caseins dissociated from the micelles in the serum phase of milk (Pitkowski et al., 2008; Dalgleish, 2011) may be further associated because of hydrophobic interactions. Cryo TEM images of milks with calcium depleted by 60 and $80 \%$ indicated the presence of smaller sized, less dense granular particles of the disintegrated casein micelles remaining in the suspension (Marchin et al., 2007). In the current work, we expected the milks with different calcium contents would have different iron-binding properties.

\section{Addition of Iron to CDM}

We added 5 different levels of ferric iron as ferric chloride $(5,10,15,20$, and $25 \mathrm{mM})$ to different CDM and determined the changes in the particle characteristics.

\section{Particle Diameter}

The Z-average diameters of normal milk and the low-CDM remained fairly constant, regardless of the concentration of added iron (Figure 2A). The Z-average diameters of the medium-CDM were substantially lower and remained at $\sim 127 \mathrm{~nm}$ up to $15 \mathrm{~m} M$ added iron. An increase was observed at $25 \mathrm{~m} M$ added iron, although the value $(184 \mathrm{~nm})$ was lower than that of normal milk. In contrast, the Z-average diameter of the high-CDM decreased gradually with increasing levels of iron addition.

The number average diameter values (data not shown) for normal milk and the low-CDM were lower than the Z-average diameter values, but the trends were similar. The diameter values remained fairly constant with iron addition, suggesting that the integrity of the casein micelles was preserved. However, for the medium- and high-CDM, the trends for the number diameters were different from those for the Z-average diameters. The high- and medium-CDM had similar sized particles upon iron addition, although the values for the medium-CDM were marginally higher than those for the high-CDM. Although we observed a slight increase in the number diameter for the medium-CDM at $25 \mathrm{mM}$ added iron, the extent of the change was substantially lower than that for the Z-average diameter. The Z-average diameter is based on the intensity variation observed for the particles under Brownian motion, which is biased toward the relatively larger aggregates. The differences in the number average diameter and the Z-average diameter for the medium-CDM at $25 \mathrm{mM}$ added iron indicated that only a fraction of the particles were aggregated into relatively larger aggregates.

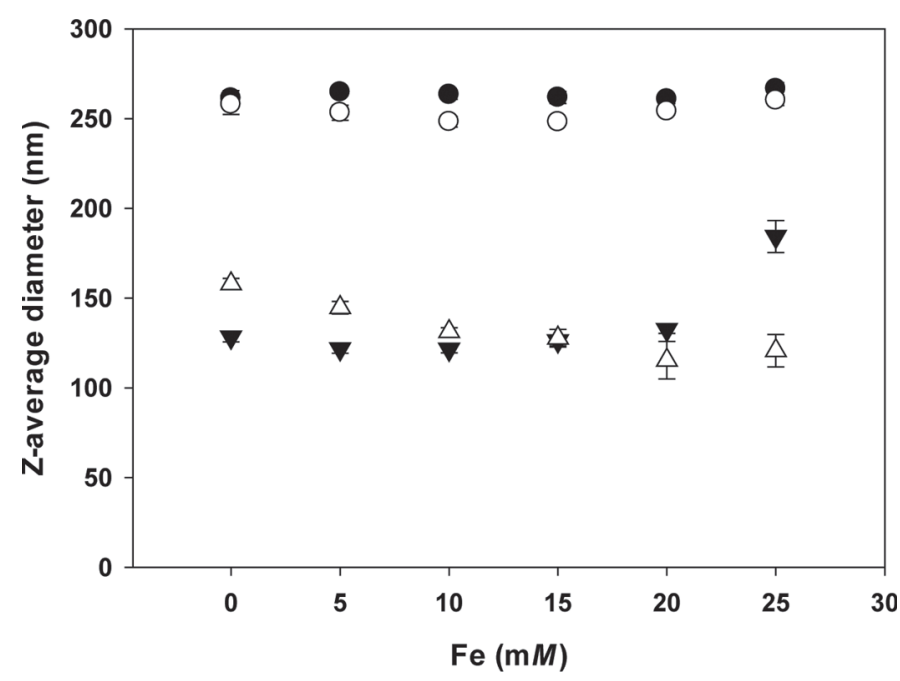

Figure 2. Effect of iron addition on the hydrodynamic mean (Z-average) diameter of normal milk $(\bullet)$, low-calcium-depleted milk $(\mathrm{CDM} ; \mathrm{O})$, medium-CDM $(\boldsymbol{\nabla})$, and high-CDM $(\Delta)$. Error bars indicate SE. 


\section{$\zeta$-Potential}

We observed negative $\zeta$-potential values, which ranged from -14 to $-17 \mathrm{mV}$ for all milk samples, irrespective of their calcium content, and these values did not change upon iron addition up to $25 \mathrm{mM}$ (Figure 3). The results were in agreement with the trends observed by Raouche et al. (2009a), who reported that the $\zeta$-potential values were little affected on the addition of up to $20 \mathrm{~m} M$ ferric iron to skim milk. For the mediumand high-CDM, slightly higher negative $\zeta$-potential values were observed for the high-CDM at all levels of iron addition. Ferric iron is positively charged and its binding to the negatively charged phosphoserine residues on the caseins is expected to reduce the overall charge of the protein-iron complex formed. However, this was not the case in any of the milks, irrespective of their total calcium content. It was probable that, in the normal milk and the low-CDM, in which the casein micelle structure remained intact upon iron addition, the added iron bound to the interior of the micelle structure, leaving the surface negative charge contributed by $\kappa$-CN largely unaffected. The $\zeta$-potential values for the medium- and high-CDM suggested that the negative charge was also retained in the newly formed structures, although the aggregation states of the caseins in these milks were markedly different.

\section{Microstructure}

The TEM image of the high-CDM did not show the presence of any dense structure, but we observed dense fibrous structures upon iron addition (Figure 4). The microstructures were similar in samples containing different concentrations of iron $(5,15$, and $25 \mathrm{mM})$ and consisted of dense, small circular particles with curved fibrous tails. These structures did not form into a larger network even at the highest level of added iron (25 $\mathrm{m} M$ ), which exceeded the level of calcium in normal milk.

It was clear from these observations that the roughly spherical structure of the casein micelle was specific to the presence of calcium in milk and could not be reformed by ferric iron under the conditions of our experiment. Although both ions bound to similar sites on the caseins, the differences in aggregation were probably due to the type of bonds involved or their respective oxidation states or both. Caseins bind to calcium phosphate nanoclusters via electrostatic interactions in milk, whereas coordination bonds are involved in the binding of iron to casein (Hegenauer et al., 1979c). Furthermore, it has been reported that a cluster of at least 3 phosphoserine residues is required for the efficient binding of casein to colloidal calcium phosphate (Aoki et al., 1992). However, only 2 phosphoserine residues are needed to satisfy the coordination requirement for the binding of ferric iron to casein (Hegenauer et al., 1979c). The type of bonds and the number of phosphoserine residues involved in interactions could be the reason for the observed differences in the structures of protein aggregates.

\section{Proteins and Minerals}

The effects of iron addition on the distribution of nonsedimentable (soluble) iron, protein, calcium, and phosphorus in normal milk, and the low-, medium-, and high-CDM are shown in Figure 5. Overall, iron, protein, and calcium followed similar trends in all milks, irrespective of their total calcium content. More importantly, a part of the added iron was always associated with the nonsedimentable phase of all samples.

Ferric iron is soluble under acid conditions $(\mathrm{pH}$ $\sim 1.9$ ) but at $\mathrm{pH}>3.5$ it forms an insoluble brick-red precipitate (Crabb and Moore, 2010). The presence of iron in the nonsedimentable phase of our samples indicated that the solubility of ferric iron was altered by the presence of milk proteins. Among the proteins in milk (whey proteins and caseins), added iron binds mostly to caseins, irrespective of their state of aggregation. Caseins, especially $\alpha_{\mathrm{s}}\left(\alpha_{\mathrm{s} 1}+\alpha_{\mathrm{s} 2}\right)$ - and $\beta-\mathrm{CN}$, contain clusters of phosphoserine residues, which bind iron strongly (Horne, 1998), primarily via coordination links with oxygen (Gaucheron, 2000).

In normal milk, $\sim 26 \%$ of the total protein and $\sim 31 \%$ of the total calcium were associated with the nonsedimentable phase and were not significantly affected by

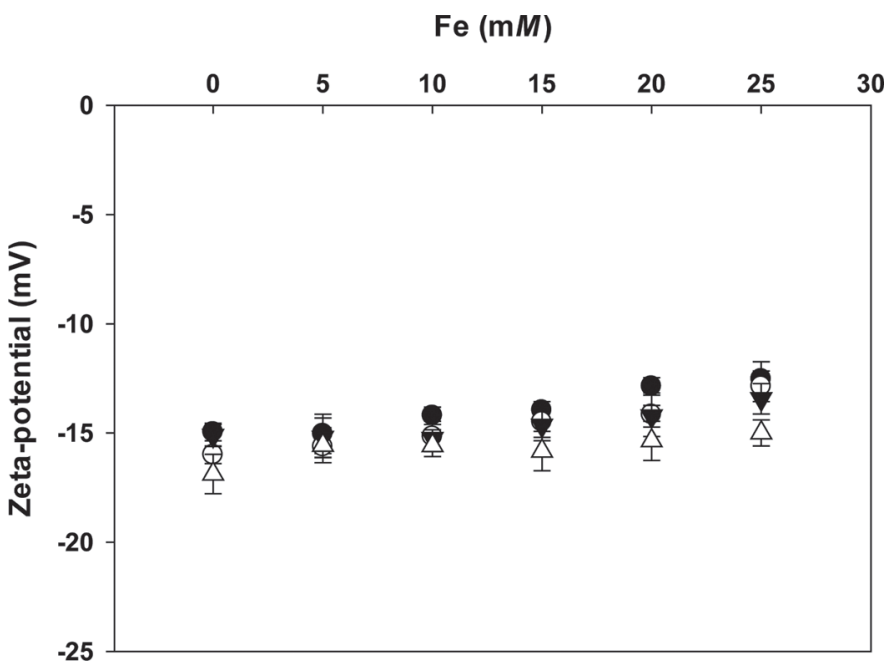

Figure 3. Effect of iron addition on the $\zeta$-potential of normal milk $(\bullet)$, low-calcium-depleted milk $(\mathrm{CDM})(\bigcirc)$, medium-CDM $(\mathbf{v})$, and high-CDM $(\Delta)$. Error bars indicate SE. 
iron addition (Figure 5A). Approximately $44 \%$ of the total phosphorus was present in the nonsedimentable phase of normal milk, which reduced to $\sim 10 \%$ upon the addition of $25 \mathrm{mM}$ iron. Less than $15 \%$ of the total iron was associated with the nonsedimentable phase at all levels of addition.

The depletion of $\sim 20 \%$ calcium from normal milk resulted in $\sim 10 \%$ increase in the nonsedimentable protein and phosphorus content in the low-CDM (Figure $5 \mathrm{~B})$. The addition of iron to this system decreased the proportions of nonsedimentable protein and calcium, which reached similar proportions to those in normal milk at the $25 \mathrm{mM}$ level. Phosphorus was most affected, with $\sim 15 \%$ of the total phosphorus remaining in the nonsedimentable phase upon the addition of $25 \mathrm{mM}$ iron. The proportion of iron in the nonsedimentable phase decreased at all levels of addition, with $\sim 7 \%$ of the added iron remaining in the nonsedimentable phase at $25 \mathrm{mM}$ added iron. The trends observed showed that added iron bound mostly to the casein micelles, in agreement with previous work (Hegenauer et al., 1979b; Gaucheron et al., 1997; Hekmat and McMahon, 1998). The majority of the calcium present in normal milk and the low-CDM was also associated with the nonsedimentable phase, irrespective of the iron content.

As the binding affinity of iron to casein is higher than that of calcium to casein, the exchange of iron with calcium in the casein micelle has been advocated (Hegenauer et al., 1979a). However, we found that calcium was not released into the nonsedimentable phase, even upon the addition of $20 \mathrm{mM}$ iron to milk (Figure $5 \mathrm{~A})$. Therefore, it was probable that the calcium, if displaced upon iron addition, remained associated with the casein micelle in some way. It is possible that the binding sites on the casein micelle were shared by calcium and added iron.

Substantially higher proportions of proteins $(>80 \%)$ and phosphorus remained in the nonsedimentable phase of the medium- and high-CDM, which presumably consisted of solubilized caseins and the whey proteins. The addition of iron resulted in a concentration-dependent decrease in the proportions of nonsedimentable protein, calcium, and phosphorus in the medium-CDM, with considerable reductions above $10 \mathrm{~m} M$ iron addition. We also observed similar trends for the proportion of added iron in the nonsedimentable phase at all levels of addition. At the highest level of iron addition $(25 \mathrm{mM})$, we found $\sim 40, \sim 28, \sim 15$, and $\sim 19 \%$ of the total protein, calcium, iron, and phosphorus in the nonsedimentable phase, respectively. We observed positive linear correlations between the proportions of protein, iron, calcium, and phosphorus in the nonsedimentable phase of the medium-CDM (data not presented), suggesting that iron, calcium, and phosphorus were bound to the
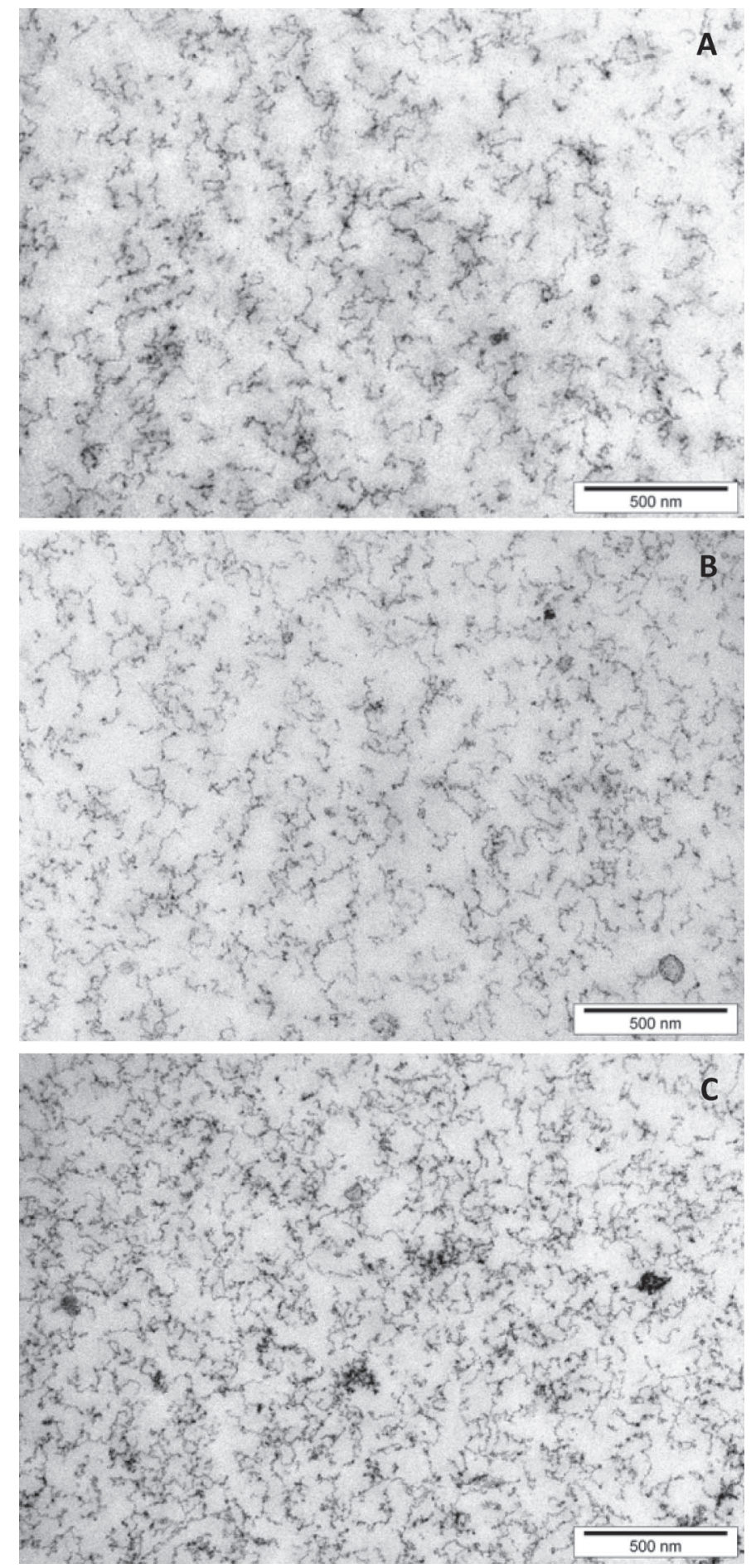

Figure 4. Transmission electron microscopy micrographs of highcalcium-depleted milks containing (A) 5, (B) 15, and (C) $25 \mathrm{mM}$ iron.

sedimentable proteins in the medium-CDM. Despite these reductions, higher proportions of all the above components were present in the nonsedimentable phase of the medium-CDM, compared with normal milk and the low-CDM. 

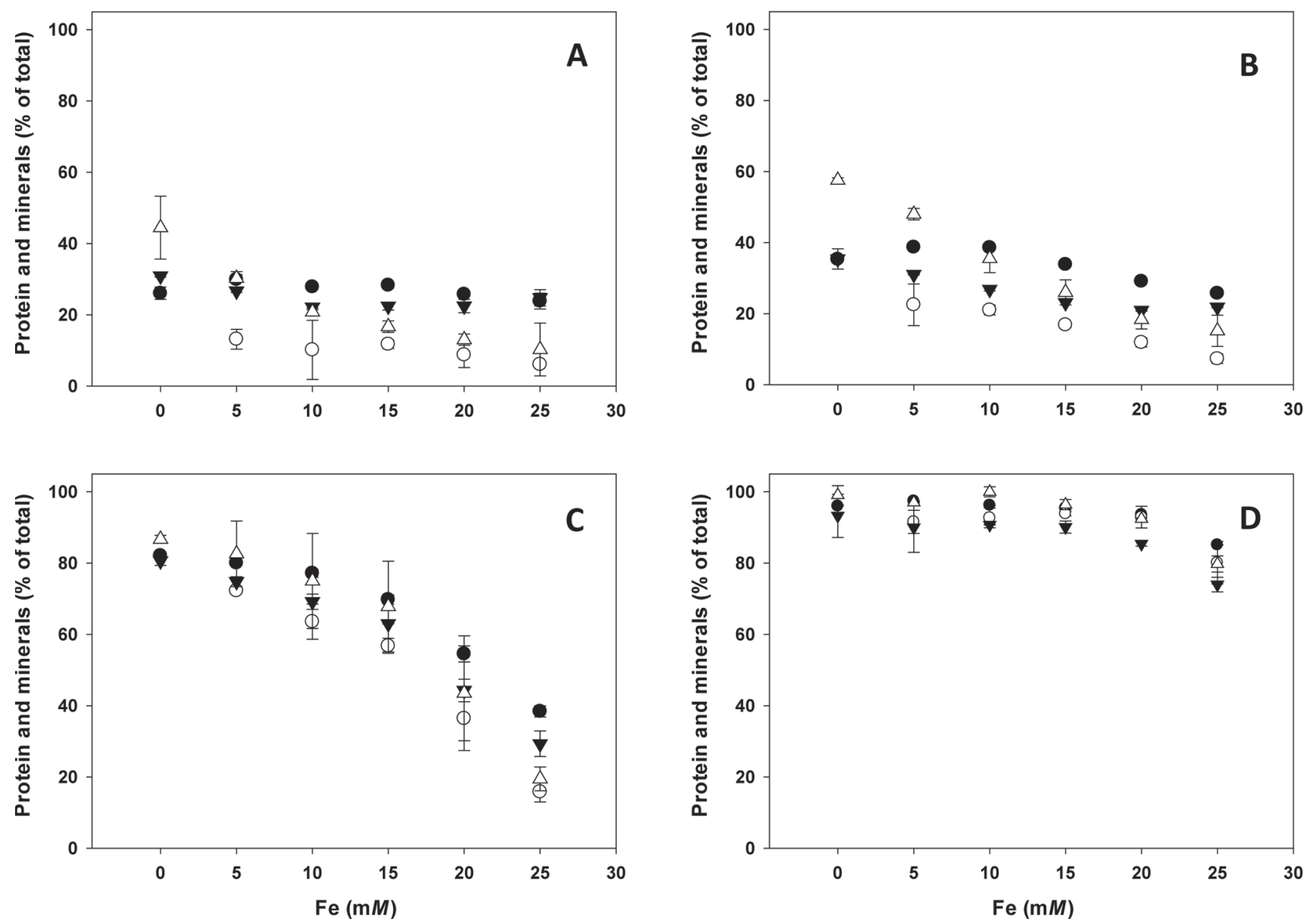

Figure 5. Effect of iron addition $(5,10,15,20$, and $25 \mathrm{mM})$ on proportional distribution of protein $(\mathbf{\bullet})$, iron $(\bigcirc)$, calcium( $(\mathbf{\nabla})$, and phosphorus $(\Delta)$ in the nonsedimentable phase (supernatant; $100,000 \times g$ for $1 \mathrm{~h}$ at $20^{\circ} \mathrm{C}$ ) of $(\mathrm{A})$ normal milk, (B) low-calcium-depleted milk $(\mathrm{CDM}),(\mathrm{C})$ medium-CDM, and (D) high-CDM. Error bars indicate SE.

Among all the milks, the high-CDM had the lowest concentration of calcium ( $\sim 30 \%$ of that in normal milk) and therefore the highest proportion of protein in the nonsedimentable phase (Figure 5D). The nonsedimentable protein content of the high-CDM was not affected at up to $20 \mathrm{~m} M$ added iron, but a slight reduction at the $25 \mathrm{~m} M$ level was observed. Approximately $80 \%$ of the total protein was still retained in the nonsedimentable phase of the high-CDM, even after the addition of $25 \mathrm{~m} M$ iron. The high-CDM had $>90 \%$ of the added iron (up to $20 \mathrm{mM}$ ) in the nonsedimentable phase, with a minor reduction at $25 \mathrm{mM}$. Both calcium and phosphorus were present mainly $(>90 \%)$ in the nonsedimentable phase of the high-CDM up to $20 \mathrm{mM}$ iron addition, but decreased slightly at $25 \mathrm{mM}$. The results suggest that at least part of the calcium and phosphorus was associated with the protein and added iron even in the high-CDM.
The SDS-PAGE analysis on the supernatants showed that the addition of iron to milk decreased the concentration of nonsedimentable caseins, with almost no caseins present at $25 \mathrm{~m} M$ added iron (Figure 6A). However, unlike the caseins, the whey proteins remained in the nonsedimentable phase of milk and high-CDM milk at all levels of iron addition (Figure 6B). Thus the higher proportion of iron in the nonsedimentable phase of high-CDM was due to the presence of caseins, which have a higher affinity and capacity to bind iron. Quantitatively, $\sim 41 \mathrm{mg}$ of iron was bound per gram of protein in the nonsedimentable phase at the $25 \mathrm{mM}$ iron addition level, which corresponded to a 4-fold increase compared with normal milk. To our knowledge, this concentration of iron in the soluble phase of milk is the highest reported to date.

An interesting aspect of our results was the difference in the proportionate distribution of iron in the me- 

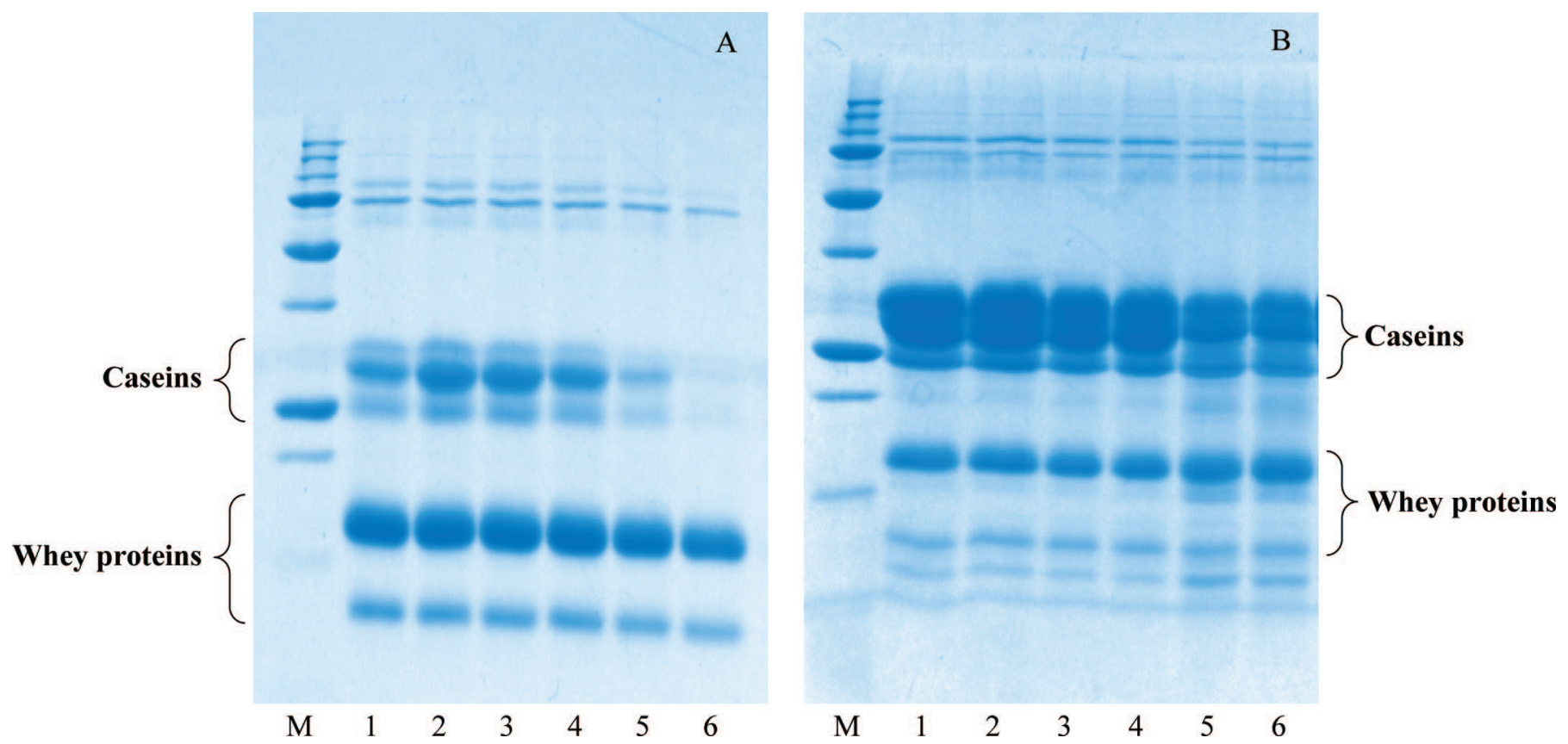

Figure 6. The SDS-PAGE gel of the supernatant $\left(100,000 \times g\right.$ for $1 \mathrm{~h}$ at $\left.20^{\circ} \mathrm{C}\right)$ in $(\mathrm{A})$ milk and (B) high-calcium-depleted milk with different concentrations of iron. Lane $\mathrm{M}=$ marker; lanes 1 to 6 had $0,5,10,15,20$, and $25 \mathrm{~m} M$ added iron, respectively. Color version available online.

dium- and high-CDM. The depletion of calcium above a critical concentration $(>50 \%)$ from milk resulted in substantial dissociation of the casein micelles, as seen previously. Disintegration of the casein micelles results in the generation of different kinds of aggregated particles (Pitkowski et al., 2008). In the case of the medium-CDM, the casein micelles were partly dissociated; however, the nature of these particles was uncertain. The results for calcium in the nonsedimentable phase of both the medium- and high-CDM suggested that a higher proportion of calcium was bound to caseins in the nonsedimentable phase of the former (Figure 5). The higher tendency toward protein sedimentation in the medium-CDM, compared with the high-CDM, was probably due to the binding of iron to the caseins aggregated by calcium.

In contrast, relatively lower proportions of dissociated caseins in the nonsedimentable phase of the high-CDM were associated with calcium. Hence, the majority of the iron added $(>83 \%)$ to the high-CDM bound to these dissociated caseins and resulted in the formation of small nonsedimentable particles, as seen in the microstructural studies discussed previously (Figure 4). Overall, the results suggested that the distribution of protein-iron complexes between the sedimentable phase and the nonsedimentable phase was governed by the calcium contents of the respective milks.

The association of $>90 \%$ of the added iron with the nonsedimentable phase in the high-CDM upon $20 \mathrm{mM}$ iron addition was notable. Protein precipitation has been observed in sodium caseinate solutions at $<5 \mathrm{mM}$ iron addition (Gaucheron et al., 1996). The difference was probably related to the minerals present in the milk. A reduction in the concentration of soluble phosphorus in milk upon iron addition has been observed previously, with the formation of insoluble ferric phosphate (Raouche et al., 2009b). We also observed a decrease in the current study of the proportion of nonsedimentable phosphorus below the levels originally present in the milks irrespective of their calcium contents. Hence, the role of phosphate in the solubility of iron-protein complexes is interesting and worth exploring.

\section{Phosphorus in Permeate}

The phosphorus content in the permeate of normal milk and the CDM constituted the phosphorus in free form (Figure 7). Approximately $34 \%$ of the total phosphorus was present in the permeate of normal milk and increased almost 2 -fold to $\sim 70 \%$ in the high-CDM. The increase in the permeate phosphorus content of the CDM suggested that a portion of the solubilized micellar phosphorus of the casein micelle existed in a diffusible form. An increase in the concentration of diffusible phosphorus upon disintegration of the casein micelle was also observed in an earlier study (Holt et al., 1986). However, not all of the phosphorus that disintegrated from the casein micelle was diffusible, suggesting that a 


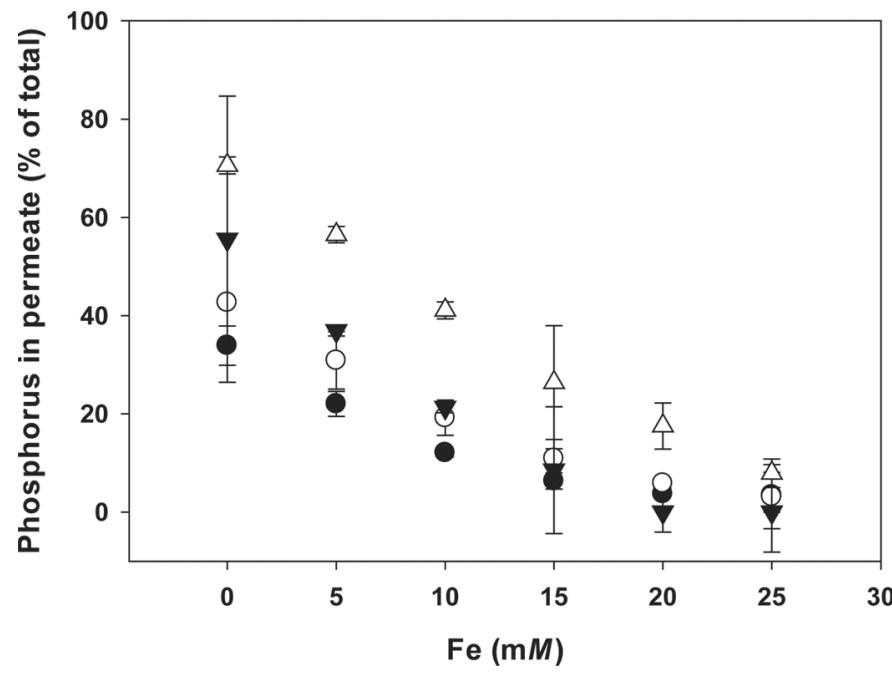

Figure 7. Effect of iron addition $(5,10,15,20$, and $25 \mathrm{mM})$ on proportional distribution of phosphorus in the permeate of milk $(\bullet)$, low-calcium-depleted milk (CDM; $)$, medium-CDM ( $\mathbf{v})$, and high$\operatorname{CDM}(\Delta)$. Error bars indicate SE.

portion was associated with the protein in the nonsedimentable phase.

A decrease in the permeate phosphorus content was observed upon iron addition to all milks, irrespective of their total calcium content. The phosphorus content in the permeate of normal milk and the low-CDM reduced almost 9-fold (to less than 6\%) upon $25 \mathrm{mM}$ iron addition. For the medium-CDM, the permeate was completely depleted of aqueous phosphorus upon 20 $\mathrm{m} M$ iron addition. However, even upon $25 \mathrm{~m} M$ iron addition in the high-CDM, $\sim 8 \%$ of the total phosphorus still remained in the permeate. The decrease in permeate phosphorus indicated that phosphorus in free form (probably ionic) was interacting with the added iron. Furthermore, the interaction of this phosphorus with iron was not affected by the concentration of calcium present in the milk. It was probable that a salt of ferric phosphate was formed upon iron addition. However, ferric phosphate is insoluble and its formation inside the hydrophobic regions of the caseins micelle has been confirmed using Mossbauer spectroscopy (Raouche et al., 2009b). The interaction of ionic phosphorus with iron, in the nonsedimentable phase of CDM, indicates that salt of ferric phosphate was probably interacting with proteins. Further work is required to elucidate the nature of these interactions in milk systems.

\section{CONCLUSIONS}

The depletion of calcium from milk by ion exchange affected its physicochemical properties, with the extent being highly dependent on the level of calcium depletion. The integrity of the casein micelles was retained at up to $\sim 20 \%$ calcium depletion from normal milk, but substantial disintegration of the casein micelles at calcium depletion levels of $>50 \%$. The properties of the milks with different calcium contents were variably affected by the addition of iron. In both normal milk and the low-CDM, the majority $(>90 \%)$ of the added iron bound to caseins within the casein micelles, minimally affecting the hydrodynamic diameter, $\zeta$-potential, and protein distribution. However, we observed a reduction in aqueous phosphorus in proportion to added iron. Protein solubility was adversely affected in the medium-CDM, whereas most of the protein and the added iron were associated with the nonsedimentable phase in the high-CDM. The solubility of protein-iron complexes in the high-CDM was related to the formation of small curved fibrous structures that resisted sedimentation upon ultracentrifugation. An interesting aspect of this study was the high concentration $(\sim 20$ $\mathrm{m} M)$ of ferric iron in the nonsedimentable phase of the high-CDM ( $\sim 70 \%$ calcium depletion). This presents a distinct advantage of the calcium depletion process over traditional processes for the iron fortification of milk systems. Overall, this work suggests that the caseins in milk could form stable nanocomplexes with ferric iron when $\sim 70 \%$ of the calcium is depleted from milk, with potential applications in liquid food products. Finally, the study highlights that the binding of iron to caseins in milk with various calcium contents is different from that in model solutions (e.g., sodium caseinate or pure caseins), mainly because of the differences in their inorganic phosphorus content.

\section{ACKNOWLEDGMENTS}

The authors thank Jianyu Chen at the Manawatu Microscopy and Imaging Centre (Palmerston North, New Zealand) for processing the samples for TEM imaging.

\section{REFERENCES}

Aoki, T., T. Umeda, and Y. Kako. 1992. The least number of phosphate groups for crosslinking of casein by colloidal calcium phosphate. J. Dairy Sci. 75:971-975.

Bernos, E., J.-M. Girardet, G. Humbert, and G. Linden. 1997. Role of the O-phosphoserine clusters in the interaction of the bovine milk $\alpha$ s1-, $\beta-, \kappa$-caseins and the PP3 component with immobilized iron (III) ions. Biochim. Biophys. Acta Protein Struct. Mol. Enzymol. 1337:149-159.

Bhaskar, G. V. 2010. Dairy product and process. Fonterra Co-Operative Group Limited, assignee. US Pat. No. US2010/0143538.

Bishov, S. J., A. S. Henick, and J. H. Mitchell. 1959. Rate of mineral removal from milk by ion exchange. J. Food Sci. 24:428-433.

Burgess, K. J. 1982. Ion exchange processing of skim-milk for food use. J. Dairy Res. 49:749.

Carmichael, D., J. Christopher, J. Hegenauer, and P. Saltman. 1975. Effect of milk and casein on the absorption of supplemental iron in the mouse and chick. Am. J. Clin. Nutr. 28:487-493. 
Crabb, E., and E. Moore. 2010. Metal uptake - Increasing the solubility of iron. Pages 31-54 in Metals and Life. 1st ed. E. Crabb and E. Moore, ed. Royal Society of Chemistry, Cambridge, UK.

Dalgleish, D. G. 2011. On the structural models of bovine casein micelles-review and possible improvements. Soft Matter 7:22652272 .

Davies, D. T., and J. C. D. White. 1960. The use of ultrafiltration and dialysis in isolating the aqueous phase of milk and in determining the partition of milk constituents between the aqueous and disperse phases. J. Dairy Res. 27:171-190.

Demott, B. J., and B. Dincer. 1976. Binding added iron to various milk proteins. J. Dairy Sci. 59:1557-1559.

DeSilva, F. J. 1999. Essentials of ion exchange. Pages 1-5 in Proc. 25th Annual WQA Conf. Fla. Resintech, West Berlin, NJ.

Douglas, F. W., N. H. Rainey, N. P. Wong, L. F. Edmondson, and D. E. LaCroix. 1981. Color, flavor, and iron bioavailability in ironfortified chocolate milk. J. Dairy Sci. 64:1785-1793.

Gaucheron, F. 2000. Iron fortification in dairy industry. Trends Food Sci. Technol. 11:403-409.

Gaucheron, F. 2005. The minerals of milk. Reprod. Nutr. Dev. 45:473-483.

Gaucheron, F., M. H. Famelart, and Y. LeGraet. 1996. Iron-supplemented caseins: Preparation, physicochemical characterization and stability. J. Dairy Res. 63:233-243.

Gaucheron, F., Y. Le Graet, K. Raulot, and M. Piot. 1997. Physicochemical characterization of iron supplemented skim milk. Int Dairy J. 7:141-148.

Grimley, H. J., A. S. Grandison, and M. J. Lewis. 2010. The effect of calcium removal from milk on casein micelle stability and structure. Milchwissenschaft 65:151-154.

Hegenauer, J., P. Saltman, D. Ludwig, L. Ripley, and P. Bajo. 1979a Effects of supplemental iron and copper on lipid oxidation in milk. 1. Comparison of metal complexes in emulsified and homogenized milk. J. Agric. Food Chem. 27:860-867.

Hegenauer, J., P. Saltman, D. Ludwig, L. Ripley, and A. Ley. 1979b. Iron-supplemented cow milk. Identification and spectral properties of iron bound to casein micelles. J. Agric. Food Chem. 27:12941301.

Hegenauer, J., P. Saltman, and G. Nace. 1979c. Iron(III)-phosphoprotein chelates: stoichiometric equilibrium constant for interaction of iron(III) and phosphorylserine residues of phosvitin and casein. Biochemistry 18:3865-3879.

Hekmat, S., and D. J. McMahon. 1998. Distribution of iron between caseins and whey proteins in acidified milk. Lebenson. Wiss. Technol. 31:632-638.

Holt, C., D. T. Davies, and A. J. R. Law. 1986. Effects of colloidal calcium phosphate content and free calcium ion concentration in the milk serum on the dissociation of bovine casein micelles. J. Dairy Res. 53:557.

Horne, D. S. 1998. Casein interactions: Casting light on the black boxes, the structure in dairy products. Int. Dairy J. 8:171-177.

Hurrell, R. F. 2002. Fortification: Overcoming technical and practical barriers. J. Nutr. 132:806S-812S.

ISO. 1987. Water for analytical laboratory use. Specification and test methods. Specification and test methods. ISO 3696:1987. International Organization for Standardization (ISO), Geneva Switzerland.
ISO. 2006. Milk-Determination of total phosphorus content-Method using molecular absorption spectrometry. Interna ional standard. ISO 9874:2006. International Organization for Standardization (ISO), Geneva, Switzerland.

Karlsson, A. O., R. Ipsen, and Y. Ardö. 2007. Observations of casein micelles in skim milk concentrate by transmission electron microscopy. Lebenson. Wiss. Technol. 40:1102-1107.

King, R. L., J. R. Luick, I. I. Litman, W. G. Jennings, and W. L. Dunkley. 1959. Distribution of natural and added copper and iron in milk. J. Dairy Sci. 42:780-790

Lin, M. J., A. Grandison, X. Chryssanthou, C. Goodwin, A. Tsioulpas, A. Koliandris, and M. Lewis. 2006. Calcium removal from milk by ion exchange. Milchwissenschaft 61:370-374.

Lyman, J. F., E. H. Browne, and H. E. Otting. 1933. Readjustment of salts in milk by base exchange treatment. Ind. Eng. Chem. $25: 1297-1298$.

Marchin, S., J.-L. Putaux, F. Pignon, and J. Leonil. 2007. Effects of the environmental factors on the casein micelle structure studied by cryo transmission electron microscopy and small-angle $\mathrm{x}$ ray scattering/ultrasmall-angle x-ray scattering. J. Chem. Phys. 126:045101.

Marshall, M. 2010. Ash analysis. Pages 105-116 in Food Analysis. 4 ed. S. S. Nielsen, ed. Springer, London, UK.

McLean, E., M. Cogswell, I. Egli, D. Woidyla, and B. de Benoist. 2009. Worldwide prevalence of anaemia, WHO Vitamin and Mineral Nutrition Information System, 1993-2005. Public Health Nutr. $12: 444-454$.

Patton, J., and W. Reeder. 1956. New indicator for titration of calcium with (ethylenedinitrilo) tetraacetate. Anal. Chem. 28:1026-1028.

Pierre, A., and G. Brule. 1981. Mineral and protein equilibria between the colloidal and soluble phases of milk at low temperature. J. Dairy Res. 48:417-428.

Pitkowski, A., T. Nicolai, and D. Durand. 2008. Scattering and turbidity study of the dissociation of casein by calcium chelation. Biomacromolecules 9:369-375.

Ranjith. H. M. P., M. J. Lewis, and D. Maw. 1999. Production of calcium-reduced milks using an ion-exchange resin. J. Dairy Res. $66: 139-144$.

Raouche, S., M. Dobenesque, A. Bot, A. Lagaude, and S. Marchesseau. 2009a. Casein micelles as a vehicle for iron fortification of foods. Eur. Food Res. Technol. 229:929-935.

Raouche, S., S. Naille, M. Dobenesque, A. Bot, J. Jumas, J. Cuq, and S. Marchesseau. 2009b. Iron fortification of skim milk: Minerals and 57Fe Mössbauer study. Int. Dairy J. 19:56-63.

Richard, H. 1999. Iron. Pages 54-83 in The Mineral Fortification of Foods. 1st ed. H. Richard, ed. Leatherhead Food RA, Surrey, UK.

Udabage, P., I. R. McKinnon, and M.-A. Augustin. 2000. Mineral and casein equilibria in milk: effects of added salts and calciumchelating agents. J. Dairy Res. 67:361.

Ward, B. R., S. J. Goddard, M. A. Augustin, and I. R. McKinnon. 1997. EDTA-induced dissociation of casein micelles and its effect on foaming properties of milk. J. Dairy Res. 64:495-504.

Zhang, D., and A. W. Mahoney. 1989. Effect of iron fortification on quality of cheddar cheese. J. Dairy Sci. 72:322-332. 